\title{
Effects of Yarn Specification and Yarn Count on the Weight and Drapability of "Akwete" an Ibo Traditional Fabric in Nigeria
}

\author{
Anucha Hope Ogechukwu ${ }^{1}$, Yahaya Hadiza $\mathrm{T}^{2}$, Shock Lucy $\mathrm{P}^{3}$ \\ ${ }^{1,2}$ Home Economics Department, Federal College of Education, Kano, Nigeria \\ ${ }^{3}$ Home and Rural Economics Department, Plateau State College of Agriculture Garkawa Plateau State, Nigeria
}

\begin{abstract}
Yarn specification and yarn count refers to the number of plies or threads count in both the warp and weft per one centimetre square $\left(\mathrm{cm}^{2}\right)$ in a woven fabric. It determines the heaviness, lightness and the texture of a woven fabric which invariably affects the drapability of the fabric. The purpose of this study was to ascertain through laboratory tests, the adverse cause, acceptability and the low patronage to the use of the akwete fabrics in Nigeria; and the impact of yarn specification, count, fabric thickness as the properties of the fabric. The experiment was carryout using samples of $100 \%$ Nigerian cotton wax and an akwete woven fabrics, each placed as the control and experimental products respectively, with the aid of the following instruments and equipment: cusik drape tester, drape meter Essdiel thickness gauge, empty tin (improvised apparatus), standard counting glass, and a thermometer in a textile design laboratory at Ahmadu Bello University Zaria, Kaduna State, Nigeria. The findings of the study revealed that yarn count and fabric thickness had significant effect on the weight and drapability to the akwete woven fabric. In view of the findings, the study recommended that for the akwete woven fabric to be light in weight and comfortable to the wearer, the yarn count must be reduced to gain a less fabric thickness and rayon yarns should be used while weaving instead of cotton yarns to improve the texture and the appearance of the fabric.
\end{abstract}

Keywords: Akwete Fabric, Drapability, Ibo Traditional Wear, Yarn Count, Yarn Specification

\section{INTRODUCTION}

A kwete fabric is a traditional hand-woven fabric worn by the Ibos (singular- Ibo), an ethnic group predominantly located in eastern part of Nigeria, with their dialect as Igbo language. The fabric is the first traditional hand-woven cloth by the Ibos and is originated from Ndoki town of Akwete in Ukwa East local government area, Abia State, Nigeria, where it derived its name (Akwete Fabric). The fabric is made from untreated or unrefined cotton harvested from farms among the locals. Notwithstanding, the quality of akwete fabric is highly priced among Ibo people, being used as a ceremonial clothe by both men and women during special occasions such as traditional marriage ceremonies, special cultural outings and celebrations. Otuka (2009), remarked that the Ibo women folks usually tie the cloth as wrapper with a light weighted machine-made fabric, while the men use the fabric to sew traditional shirts popularly known as "jumper" "wokor" or "etibo", which are worn over a pair of trouser. Also,
Akparanta and Otuka (2009) viewed this cloth as one of the finest local hand-woven cotton fabrics in the world, produced in Nigeria by the Akwete community. The cloth is made of pure cotton yarns, with the addition of contrasting colours of threads, heavier in texture to achieve decorative pattern and effects. Though, the fabric is marked as a special occasion wears or apparel, it has been regarded as being heavy and coarse to the skin which makes it uncomfortable to the wearer and may account for its low patronage. The fabric has also been found useful for other purposes such as for the production of articles used as designer's shoes, handbags and ties among others. Despite the economic advantages and other usefulness attributed to the use of akwete fabrics, it has not gained the desired patronage among the elites. The local weavers of the fabric are constantly on the lookout for financial and trade support that could enable them continue in the weaving business. The noticed gap in the patronage of akwete woven fabrics explains the need for research to proffering solutions for the improvement on the fabric. Also, the akwete woven fabric has not gained widespread popularity among the Ibo wearers despite its designation as a special occasion fabric.

The purpose of this study is to ascertain through laboratory tests, the adverse cause, acceptability and the low patronage to the use of the akwete fabrics in Nigeria and the impact of yarn specification, yarn count, fabric thickness as the properties of the fabric. It shall also ascertain the thermal heat and drapability rate of the fabric and proffer possible suggestions on the best way to increase acceptability and patronage of the fabric for clothing needs in Nigeria.

\section{LITERATURE REVIEW}

Many subjects in sciences have evidences of abundant researches and literatures that have discussed various issues. Conversely, the subject, Akwete fabric has shown few literatures and studies that have extensively discussed its attributes and chemistry. However, few among the studies evidenced in these studies tried and discussed on yarn properties and textures. A review among such studies include; Hussain, Datta, and Rahman (2016); Galusynski and Elliss, (1983) Among the factors identified by past studies that directly or indirectly influenced woven fabrics strength were 
yarn count, fabric thickness and others. These formed the basis for the experiment of the present study on yarn specification and yarn count to the weight and drapability of akwete woven fabric. Both studies were laboratory experimental research on woven fabrics, however, they differ in some ways - the previous studies focused on reviewing related literatures on concepts, while the present concentrated on empirical reviews that has direct relationship with laboratory results that ascertained the causes, that adversely affected the acceptability and the low patronage of the use of the akwete fabric through yarn specification, yarn count, fabric thickness. Thus:

Galusynski and Elliss (1983) conducted a research on the effects of the fabric elastic constant on dynamics of fabric formation. The analysis of wearing resistance in the study found that Brierley's formular requires some modifications of values of the coefficients $m$ and $g$ for the weft and warp faced ribs and proposed the coefficient of fabric tightness $T$, if not there should be limitations on weave structures. The study agreed with Newton's suggestion that it is possible to have fabric with different sets, yarn counts, weaves and cover factors which are equally tightly woven. Their views evidenced that factors such as; tightness, firmness, tenseness, floating index are based on either yarn specification, yarn count or weave design which has direct influence on woven fabric.

Ekumankama and Ukah (2004) carried a research titled promoting entrepreneurship in Akwete fabric production in Abia state, Nigeria, with the objective of identifying measures for promoting entrepreneurship in Akwete fabric production. Descriptive survey was used and the population comprised of the entire staff of Akwete fabric producers in the textile centres of Aba, Ministry of Arts and Culture Umuahia, and Akwete Weaving Centre in Ukwa Local government area in Aba zone, all in Abia State Nigeria. A population of 260 people involved in fabric weaving was used for the study. Purposive random sampling was used to select 100 producers as the sample population for the study, Questionnaire were administered to collect data from the respondents which was analysed using frequencies, simple percentage and mean. The findings from the study revealed that there was low demand for akwete fabric due to its heaviness in weight which in turn led to its low production rate, and also manpower was insufficient which hinders large scale production of akwete fabric.

Dauda, (2004) conducted an experimental research on the use of yarns for satisfactory construction of textiles. Three different fabrics were selected using purposive sampling method, the fabrics selected were $100 \%$ cotton, $100 \%$ polyester and a blend of polyester and cotton at 50\% each.
The study evaluated properties which were considered can be influenced by yarn type, especially for apparels and sheets. Percentage and means were used to analyse the data. The findings revealed that fabric properties like thickness, crimp, shrinkage, yarn count, air permeability, tensile strength, abrasion resistance, thermal conductivity, drapability are dependent on the yarn for satisfactory construction of textile for particular end-use. According to Dauda and Kolawole's assertion (2003), the thickness of woven fabric is usually known to be independent of the number of threads per unit length, and dependent on the bulk density of the yarns and degree of crimp interchanged between the warp and weft yarns. The fabric thickness being at its minimum when the crimp is most evenly distributed between all the yarns and increases with increasing inequality of crimp distribution.

Hossain, Datta and Rahman (2016) carried out a research titled; "A Review on Different Factors of Woven Fabrics" Strength Prediction" in Bangladesh. The study was experimental design carried out in laboratory. The study identified factors responsible for selecting the appropriate fabrics for garment or apparel manufacture. It revealed that strength is the first property that has great influence and total dependent on the intended end-use. The study explained that the strength of the fabric gave much consideration as to its desirability. Other factors considered that the fibre type or blend use, twist, fibre fineness, stiffness, fibre density, fabric structure, yarn count, yarn density, fabric thickness and the likes, also directly or indirectly influenced the woven fabrics strength. The study further revealed that compression extension, fabric thickness and weight are the important characteristics for engineering different compression garments.

\section{MATERIALS AND METHODS}

This study determined the effects of yarn specification and count on the weight and drapability of Akwete woven fabric using laboratory experimental method. Akwete woven fabric is an Ibo traditional hand-woven fabric from the Eastern part of Nigeria. The woven akwete fabric measuring $24 \mathrm{~cm}$ x $36 \mathrm{~cm}$ of $100 \%$ unrefined cotton with weft thread of 36 tex and warp thread of 48 tex was used as the specimen for the control experiment as shown in figure 1 . While the $100 \%$ refined Nigerian cotton wax fabric measuring $24 \mathrm{~cm} \times 36 \mathrm{~cm}$ with weft thread of 28 tex and warp thread of 16 tex was adopted as the control experiment.

The experiment was carried out in a textile design laboratory at Ahmadu Bello University Zaria, Kaduna State Nigeria using the following equipment and instruments: cusik drape tester, drape meter, essdiel thickness gauge, empty tin as an improvised apparatus, a counting glass, thermometer and two samples of fabrics. 


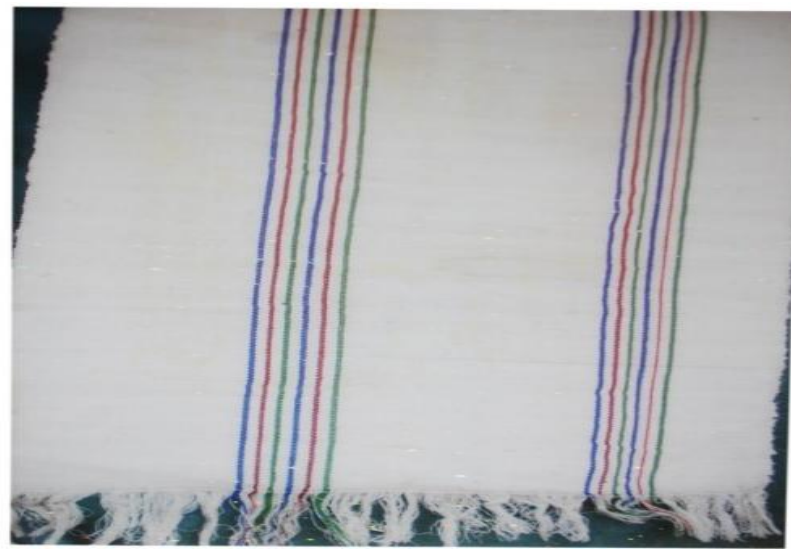

Figure 1: An Illustration of the Akwete Cotton Fabrics

Source: Researchers Laboratory Procedural Image

\subsection{Experimental Procedures and Results}

This study adopted an experimental design procedure, using a laboratory method for testing the fabric properties such as the yarn specification, yarn count, fabric thickness, thermal heat and drapability of the two sampled fabrics to determine the effect of the properties on weight and drapability on both fabrics. The experiment was carried in the textile design laboratory section of Faculty of Engineering, Ahmadu Bello University Zaria, and Kaduna State, Nigeria. The experiment was done using the following instruments and equipment; counting glass, Essdiel fabric guage, drape meter, cusick drape tester, improvise tin for thermal conductivity, thermometer.

The following procedures were observed during experiment. Thus:

i. Yarn Specification: The yarn specimens were removed from warp and weft directions of both fabrics respectively and counted. The threads were counted in tex one centimetre of the fabric, measured by $17 \mathrm{~cm}$ and cut, at random then the rows of the yarns were detected and each row was stripped open and counted to know the number plies.

The number of threads per centimetre of each fabric were determined according to the specification in BS. 2865 method. A counting glass was used and five readings were taken for warp and weft threads randomly from both fabrics as shown in Figure 1. Table 1 shows the result of the mean for each fabric.

Table 1: Readings, and Mean Value of the Warp and Weft Threads of both Fabrics

\begin{tabular}{|c|c|c|c|c|c|c|c|c|c|}
\hline \multirow[b]{2}{*}{$\mathrm{S} / \mathrm{N}$} & \multicolumn{5}{|c|}{ Experimental Product } & \multicolumn{4}{|c|}{ Control Product } \\
\hline & Readings & $\begin{array}{c}\text { No. of } \\
\text { Plies/cm }\end{array}$ & $\begin{array}{l}\text { Yarn } \\
/ \mathrm{cm}\end{array}$ & Total plies $/ \mathrm{cm}^{2}$ & $\begin{array}{c}\text { Grand } \\
\text { Total }\end{array}$ & $\begin{array}{c}\text { No. of } \\
\text { Plies/cm }\end{array}$ & $\begin{array}{l}\text { Yarn } \\
/ \mathrm{cm}\end{array}$ & $\begin{array}{c}\text { Total } \\
\text { plies } / \mathrm{cm}^{2}\end{array}$ & $\begin{array}{c}\text { Grand } \\
\text { total }\end{array}$ \\
\hline 1 & $\begin{array}{l}\text { Warp } \\
\text { Weft }\end{array}$ & $\begin{array}{c}11 \\
6\end{array}$ & $\begin{array}{l}1 \\
1\end{array}$ & $\begin{array}{c}4 \times 11+4=48 \\
6 \times 6=36\end{array}$ & 1,728 & $\begin{array}{l}1 \\
1\end{array}$ & $\begin{array}{l}1 \\
1\end{array}$ & $\begin{array}{l}1 \times 31=31 \\
1 \times 16=16\end{array}$ & 490 \\
\hline 2 & $\begin{array}{l}\text { Warp } \\
\text { Weft }\end{array}$ & $\begin{array}{c}11 \\
6 \\
\end{array}$ & $\begin{array}{l}1 \\
1 \\
\end{array}$ & $\begin{array}{c}4 \times 11+2=46 \\
6 \times 6=36\end{array}$ & 1,656 & $\begin{array}{l}1 \\
1 \\
\end{array}$ & $\begin{array}{l}1 \\
1 \\
\end{array}$ & $\begin{array}{l}1 \times 28=28 \\
1 \times 16=16\end{array}$ & 448 \\
\hline 3 & $\begin{array}{l}\text { Warp } \\
\text { Weft }\end{array}$ & $\begin{array}{c}13 \\
6 \\
\end{array}$ & $\begin{array}{l}1 \\
1\end{array}$ & $\begin{array}{l}4 \times 13=52 \\
6 \times 6=36\end{array}$ & 1,872 & $\begin{array}{l}1 \\
1 \\
\end{array}$ & $\begin{array}{l}1 \\
1\end{array}$ & $\begin{array}{l}1 \times 29=29 \\
1 \times 16=16\end{array}$ & 464 \\
\hline 4 & $\begin{array}{l}\text { Warp } \\
\text { Weft }\end{array}$ & $\begin{array}{c}11 \\
6 \\
\end{array}$ & $\begin{array}{l}1 \\
1\end{array}$ & $\begin{array}{c}4 \times 11+3=47 \\
6 \times 6=36\end{array}$ & 1,692 & $\begin{array}{l}1 \\
1\end{array}$ & $\begin{array}{l}1 \\
1\end{array}$ & $\begin{array}{l}1 \times 25=25 \\
1 \times 16=16\end{array}$ & 400 \\
\hline 5 & $\begin{array}{l}\text { Warp } \\
\text { Weft }\end{array}$ & $\begin{array}{c}11 \\
6\end{array}$ & $\begin{array}{l}1 \\
1\end{array}$ & $\begin{array}{c}4 \times 11+4=48 \\
6 \times 6=36\end{array}$ & 1,728 & $\begin{array}{l}1 \\
1\end{array}$ & $\begin{array}{l}1 \\
1\end{array}$ & $\begin{array}{l}1 \times 27=27 \\
1 \times 16=16\end{array}$ & 432 \\
\hline & & $\begin{array}{l}\text { s in } \mathrm{Cm}^{2} \text { of } \\
\mathrm{n}: 1,735.2 \mathrm{p}\end{array}$ & $\begin{array}{l}\text { reading } \\
\mathrm{Cm}^{2}\end{array}$ & & 8,676 & Total plies & $\begin{array}{r}n^{2} \text { of fiv } \\
446.8 \\
\end{array}$ & dings mean: & 2,234 \\
\hline
\end{tabular}

Source: Researchers' laboratory Computations, 2020

Table 1 showed that in one centimetre square of five readings for both fabrics. The total plies found were 8,676 on the experimental product and 2,234 on the control product. The result revealed that there was higher concentration of plies in one centimetre of Akwete fabric being the experimental product than as found in the Nigerian cotton wax being the control product. The greater number of plies constitute to the heavy weight of the akwete fabric. The Table further depict that the yarn count on the Nigerian Cotton fabric was made with lesser and fewer quantities of yarn while the akwete fabric constitute more plies of yarns. The more plies of yarns could not freely allow for temperature drop and air penetration. This has made it uncomfortable to the body if it is used in making dresses.

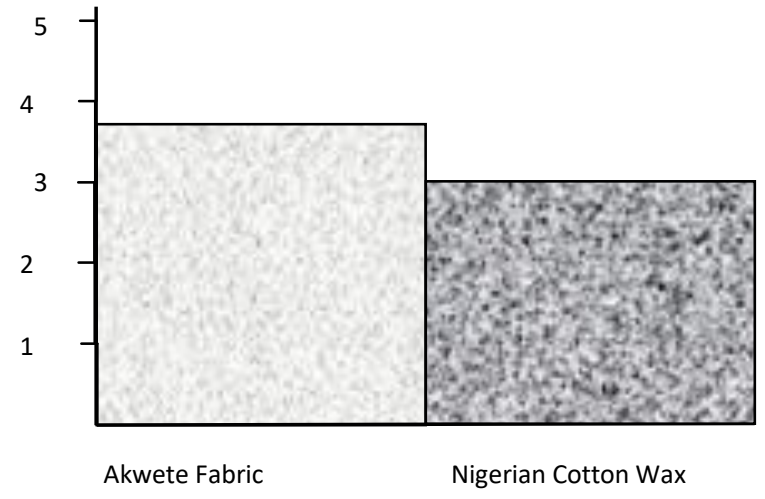

Figure 2: BS Reading Glass counting Specification Source: Researchers Laboratory Procedural Image 
Thus, the implication is that any fabric with such high concentration of yarns tends to be thick and heavy, which could cause the wearer uncomfortable, while the same type of cloth made with a Nigerian cotton fabric would be of better comfort to the same wearer. The control product has 2,234 plies of yarns in five readings indicating lighter weight and being comfort to the body whenever it shall be used. The result of the experiment revealed that the akwete fabric was made of basket wave which has double set of yarns making it tight and compact, thus constituted the indication to its heavier weight. This further revealed a very high concentration of yarns to 1,735 plies per one centimetre square $\left(1 \mathrm{~cm}^{2}\right)$ constituting to its heaviness in weight and proportionately affecting the drapability while the Nigeria $100 \%$ cotton fabric with 446.8 plies per one-centimetre squares showed lesser weight.

Fabric thickness Test: Each of the samples of the fabrics were placed between the anvil and the presser of the "Essdiel thickness gauge" using a load of $20 \mathrm{gf} / \mathrm{Cm}^{2}$. The fabrics were made of $100 \%$ cotton. The presser was allowed to descend gently on the fabric as shown figure 3 . Five readings were taken for each sample and the mean calculated. The result of the calculated mean is shown in Table 2

Table 2: The Fabric Thickness

\begin{tabular}{|c|c|}
\hline $\begin{array}{c}\text { Akwete Fabric } \\
\left(\mathrm{x} 10^{-3} \mathrm{~mm}\right)\end{array}$ & $\begin{array}{c}\text { Nigerian Cotton } \\
\left(\times 10^{-3} \mathrm{~mm}\right)\end{array}$ \\
\hline 2.40 & 0.40 \\
\hline 2.60 & 0.35 \\
\hline 2.50 & 0.30 \\
\hline 2.50 & 0.35 \\
\hline 2.54 & 0.39 \\
\hline 2.45 & 0.358 \\
\hline
\end{tabular}

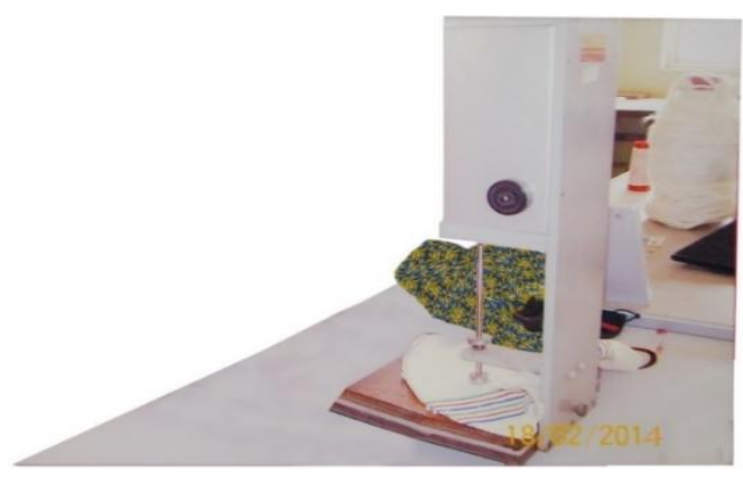

Figure 3: Testing Fabric Thickness using Essdiel Thickness Gauge

Source: Researchers' laboratory Computations, 2020

ii. Thermal Heat Test: The two samples were cut equally to $24 \mathrm{~cm} \times 36 \mathrm{~cm}$ in size and fixed differently to a round tin that formed a jacket round on the tin being an improvised apparatus, as shown Figure 4. Boiled water at $100^{\circ} \mathrm{C}$ was poured into the tin with a rubber cork. The cork had a small hole through which a thermometer was inserted.

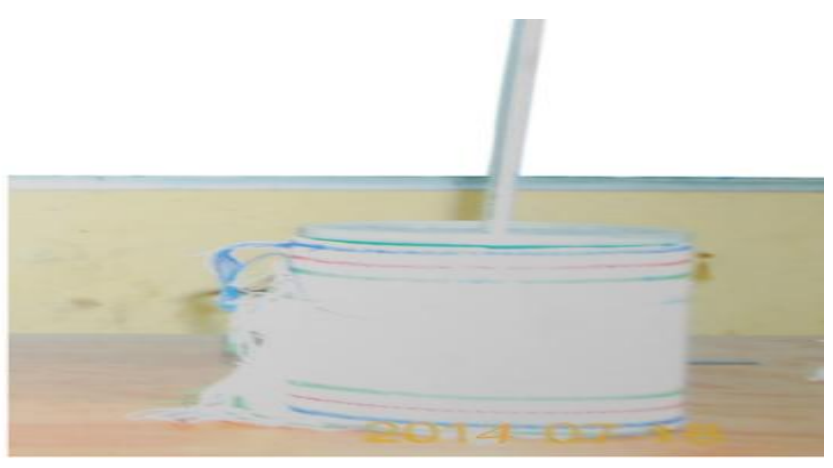

Figure 4: Thermal Heat Improvised Apparatus Source: Researchers Laboratory Procedural Image

The rate of temperature drops was taken at equal intervals of ten minutes. Table 3 shows the reading of the heat loss rate or temperature drop which was taken at intervals of ten minutes. The reading is further represented in a Thermal Heat graph in Figure 5.

Table 3: Heat Loss Rate

\begin{tabular}{|c|c|}
\hline $\begin{array}{c}\text { PA Akwete Experimental } \\
\text { Product }\end{array}$ & $\begin{array}{c}\text { PD Nigerian Wax Control } \\
\text { product }\end{array}$ \\
\hline $\mathrm{PA}^{0}$ Centrigrade/minutes & $\mathrm{PA}^{0} \mathrm{Centrigrade} /$ minutes \\
\hline $90^{\circ} \mathrm{C}$ in $0 \mathrm{mins}$ & $90^{\circ} \mathrm{C}$ in $3 \mathrm{mins}$ \\
\hline $80^{\circ} \mathrm{C}$ in $10 \mathrm{mins}$ & $70^{\circ} \mathrm{C}$ in $7 \mathrm{mins}$ \\
\hline $60^{\circ} \mathrm{C}$ in $20 \mathrm{mins}$ & $40^{\circ} \mathrm{C}$ in $12 \mathrm{mins}$ \\
\hline $40^{\circ} \mathrm{C}$ in $30 \mathrm{mins}$ & $10^{\circ} \mathrm{C}$ in $18 \mathrm{mins}$ \\
\hline $20^{\circ} \mathrm{C}$ in $40 \mathrm{mins}$ & \\
\hline $10^{\circ} \mathrm{C}$ in $50 \mathrm{mins}$ & \\
\hline
\end{tabular}

Source: Researchers' Computation

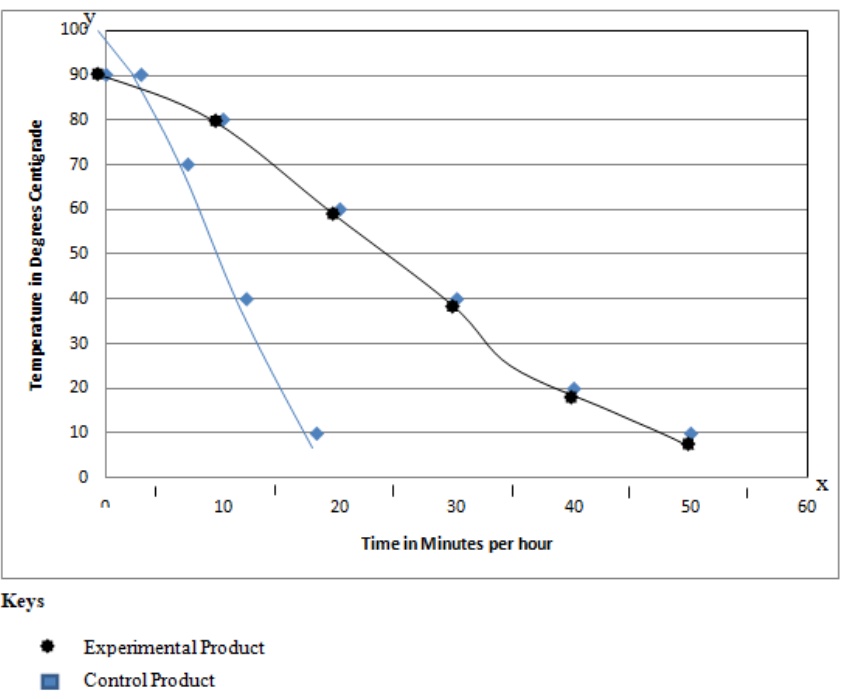

Figure 5: Thermal Heat Graph

Source: Researchers' Computation 
The y axis of the graph measured from $0^{\circ} \mathrm{C}-100^{\circ} \mathrm{C}$ degree centigrade of temperature, while the $\mathrm{x}$ axis shows from $0-60$ minutes time duration of the heat loss.

iii. Drapability Test: Figure 6 and 7 shows the application of drape meter on both Akwete fabric and Nigeria cotton wax fabrics. A sample of the fabrics piece measuring $36 \mathrm{~cm}$ in diameter each, was cut and tested for drapability, on "cusick draper tester" in accordance with BS 5058 specification. The fabric pieces were hung under the cusick draper tester for a gravitational force action. The shadow of the ring paper formed in the paper was traced out, the ring paper was weighed and recorded as $\mathrm{m}_{1}$. The outline traced was then cut out and the lower part was weighed and recorded as $\mathrm{m}_{2}$

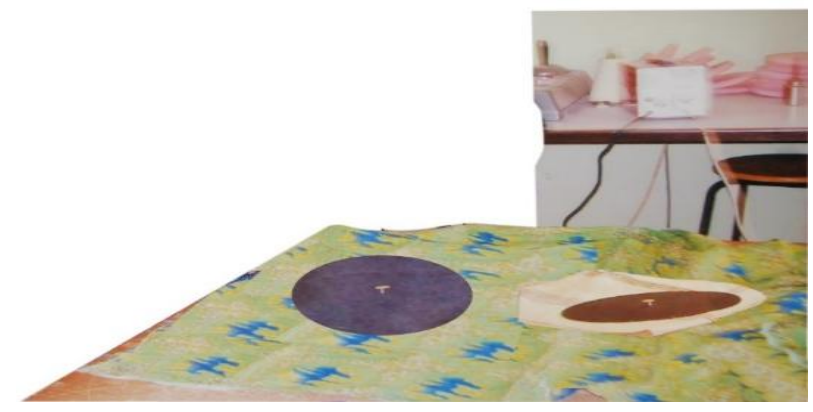

Figure 6: The Application of Drape Meter on both Akwete Fabric and Nigeria Cotton Wax Fabrics.

Source: Researchers Laboratory Procedural Image

Table 4: Result of the Drapability of Akwete Fabric (Experimental Product) and Nigerian Cotton Wax (Control Product)

\begin{tabular}{|c|c|c|c|c|c|c|c|c|c|}
\hline Samples of fabrics & Drape & 1 & 2 & 3 & 4 & 5 & Total & Average & $\begin{array}{c}\text { Drape } \\
\text { coefficient }\end{array}$ \\
\hline \multirow{2}{*}{$\begin{array}{c}\text { Experimental } \\
\text { (Akwete) }\end{array}$} & $\mathrm{m}_{1}$ & $12.18 \mathrm{~g}$ & $12.18 \mathrm{~g}$ & $12.18 \mathrm{~g}$ & $12.18 \mathrm{~g}$ & $12.18 \mathrm{~g}$ & $60.9 \mathrm{~g}$ & $12.18 \mathrm{~g}$ & \\
\cline { 2 - 12 } & $\mathrm{m}^{2}$ & $7.94 \mathrm{~g}$ & $8.20 \mathrm{~g}$ & $8.20 \mathrm{~g}$ & $7.75 \mathrm{~g}$ & $7.50 \mathrm{~g}$ & $39.5 \mathrm{~g}$ & $7.92 \mathrm{~g}$ & $65.02 \mathrm{~g}$ \\
\hline $\begin{array}{c}\text { Control (Nigerian } \\
\text { wax) }\end{array}$ & $\mathrm{m}_{1}$ & $9.28 \mathrm{~g}$ & $9.25 \mathrm{~g}$ & $9.26 \mathrm{~g}$ & $9.28 \mathrm{~g}$ & $9.27 \mathrm{~g}$ & $46.34 \mathrm{~g}$ & $9.27 \mathrm{~g}$ & \\
\cline { 2 - 11 } & $\mathrm{m}^{2}$ & $3.25 \mathrm{~g}$ & $3.21 \mathrm{~g}$ & $3.23 \mathrm{~g}$ & $3.25 \mathrm{~g}$ & $3.22 \mathrm{~g}$ & $16.16 \mathrm{~g}$ & $3.23 \mathrm{~g}$ & $34.86 \mathrm{~g}$ \\
\hline
\end{tabular}

Source: Researchers' Computation

On the Nigerian cotton wax fabric (the control product). The result showed a difference of $30.16 \mathrm{~g}$. The experimental product having $65.02 \mathrm{~g}$ showed less flexibility than the control product as a result of its heavy weight due to its compactness thus, it indicates the characteristics of coarse texture signifying an uncomfortable feature to the body. The result implies that the yarn type used in weaving does not allow air to penetrate to provide cooling effect to the body of the wearer, which makes it only suitable as an apparel for cold weather.

Drape coefficient formular $=\frac{m_{2}}{m_{1}} \times \frac{100}{1}$

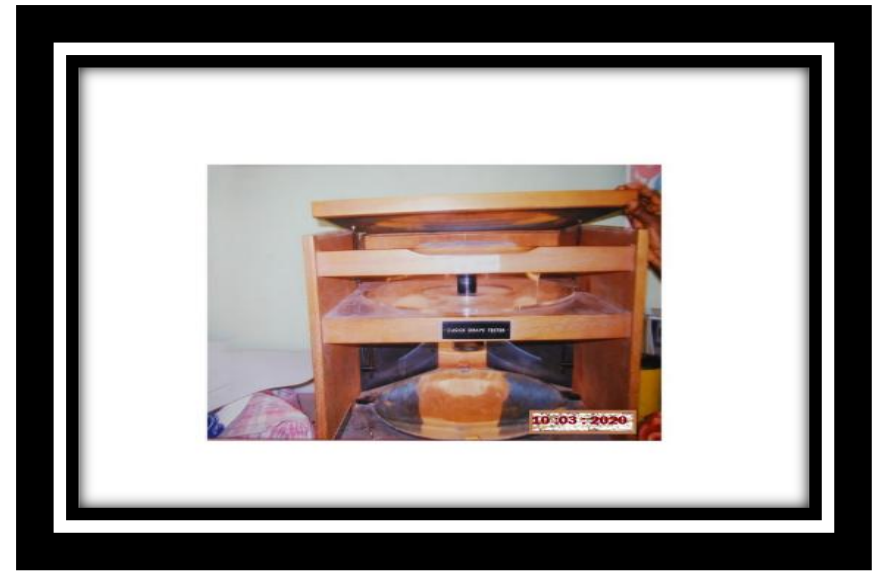

Figure 7 The Application of Cusick Drape Tester for testing the drapability of both fabrics.

Source: Researchers Laboratory Procedural Image

Table 4 shows the result of the drapability of the akwete fabric being the experimental product and the Nigerian cotton wax fabric as the control experiment product. The papers were removed and weighed for initial weight $\left(\mathrm{m}_{1}\right)$ after which the papers were cut from the traced shadows and weighed again for the final weight $\left(\mathrm{m}_{2}\right)$. The result of the reading shows the drape coefficients calculated as $65.02 \mathrm{~g}$ on the akwete fabric (the experimental product) and $34.86 \mathrm{~g}$

\section{iv. Fabric Thickness}


This corroborates with the study of Taylor, (2000) in Dauda, (2004) assertion, that compact fabrics that has high resistance to distortion shall as well have poor drape quality. This implies that heavy fabrics with coarse yarns and construction have poor drape characteristics while light fabrics from smooth yarn texture has good drape and handle.

According to Glater in Dauda and Kolawole (2003) thermal conductivity of a fabric is a function of heat transference of fibres and of the aggregate fibre-air system. The result from the experiment on the thermal heat, revealed that the akwete fabric lost heat to the atmosphere slowly at temperature of $90^{\circ} \mathrm{C}$ in 50 minutes. This indicated its compactness, thick and heavy while the Nigerian cotton wax lost its own heat to the atmosphere in 18 minutes at the temperature of $90^{\circ}$ centigrade. This further explained to the fact that the Nigerian Wax Fabric used as control experiment to this study has lighter weight suggesting it to be an attire suitable for warm season. The implication is that the heat loss allows air permeability through the opening causing the coolness of the body.

The drapability of the two sampled fabrics, revealed that the drape coefficients calculated for the akwete fabric being the experimental product while the Nigerian cotton wax as the control product showed more difference in coefficient of $30.16 \mathrm{~g}$ indicating less flexibility than the control product, due to its heaviness, and more compactness thereby making the fabric texture and more coarse texture which its effect has been an overwhelming discomfort to the body of the wearer, It further prevented sufficient air to permeate into it that could have provided good cooling effect to the human body. This result is in consonant with Dauda and Kolawole (2003) discovery that fabric properties such as thickness, crimp, shrinkage, yarn count, air permeability tensile strength, abrasion resistance, thermal conductivity and drapability are dependent on yarn type, for satisfactory construction of textiles for particular end-use. In addition, Kothari in Hossain, Datta, and Rahman, (2016) posit that the fabric mechanical and comfort related properties are related to the structural properties of linear density, twist level, thread densities, crimp levels of warp and weft, cover factor, fabric thickness and fabric skew and bow.

The findings of this study are imperative and corroborates to previous studies of Dauda \&. Kolawole (2000); Taylor (2000), and Hossain, Datta \& Rahman, (2016) it revealed the variables associated with poor demand and usage of akwete fabric formed the basis of the objective of this study. It further focused on the determination of the yarn specification and yarn count that affected the weight and drapability, and suggested reducing the yarn count and the use of rayon yarn for weaving the fabric to improve its smoothness and texture. The past studies were carried through a purposive random sampling in selecting the sample as well as the present study. The core findings of the past studies paved way to the present study as it served as a bearing in selecting the type of yarn to use to help improve the texture of akwete fabric towards making it suitable for frequent use. The compactness and heavy weight affecting the properties, and thermal heat is consistent with Taylor (2000) in Dauda (2004) that, compact fabrics which has high resistance to distortion will have poor thermal heat quality and poor drape characteristics.

The findings from this study further revealed that the akwete fabric has been affected by its yarn specification, yarn count and the type of weave (weave design) applied and has considerably made it heavier and uncomfortable for frequent wearing and as special garment for occasions, among Ibo educated elites. Furthermore, this study is related to the findings of Galusynsiki and Ellis (1983) that attributed the fabric elastic constant on dynamics of fabric formation. The present study amplified the effects of yarn specification of fabrics.

\section{CONCLUSIONS}

The titles of the past research relate to the main objective of present study on the effects of yarn specification and yarn count as it affects the weight and drapability of akwete woven fabric. Both the past and present studies used the same instrument for data collection and similar approaches to deduce findings as none relied on any tested hypothesis. This study inferred therefore, that cloths made of akwete fabric could only be suitable during cold weather periods in Nigeria, and not for frequent usage as was earlier preferred. In addition. The akwete fabric is found to be made of basket weave with double sets of yarns which made it compacted that it became not easy to neither heat loss nor air to easily penetrate to the body of the wearer of any cloth made with the fabric. It is evidenced that the akwete fabrics has been affected by its compactness and heavy weight, thereby making the properties, and thermal heat to have high resistance to distortion, poor thermal heat quality and poor drape characteristics resulting in low patronage and the creation of much desired labour opportunities.

Therefore, the weight and drapability of the fabric is dependent on the yarn specification, yarn count and fabric thickness and not the strength of the fabric is dependent solely on the strength of the yarn as previous studies suggested. Yarn count and the fabric thickness varies with different fabrics as in the case of the akwete fabric. The increase in yarn count has negative effect on weight and drapability of any fabric as it implied to akwete fabric in this study. It is concluded that the thickness of the fabric has significantly made the fabric course in texture and relatively caused the fabric to be uncomfortable to the wearer. Importantly, the different finishing treatments applied on yarn and fabric reduces its weight and increases its smoothness and flexibility, but since Akwete fabric was made of unrefined or untreated yarns the tendency for coarseness and heavy weight became obvious. However, it further concluded that Akwete fabric is suitable for cold temperate weather not for frequent usage and special occasions as it has been previously asserted. 


\section{RECOMMENDATIONS}

Based on the findings and the established conclusions the following recommendations are made:

i. Akwete fabric could be best produced with the use of industrial yarns such as rayon yarns in place of pure cotton yarns.

ii. That the yarn counts should be reduced to two plies in a yarn instead of multiple plies of yarns to minimize its heaviness in weight.

iii. The pattern of the weave should be plain and not basket weave so as to reduce its coarseness in texture and stiffness in order to enhance its flexibility and drapability which would make it comfortable to the skin.

iv. The akwete fabric should be fashioned as an attire for cold weather not for all seasons, because of its thickness and weight.

v. If cotton yarns should be used in weaving for the fabric, it should be refined cotton yarns not untreated cotton, that could cause the fabric to have lighter effect to its weight.

\section{REFERENCES}

[1] Akparanta, E. (2009). "Executive summary" Welcome to Akwete world http://Akweteworld.com/retrieved 3/5/2018 8:14pm

[2] Bello, R. and Ajayi, O. (2000). Research Methods and Statistical Analysis Ilorin Haytee Press and Publishing Company Ltd pp. 56.
[3] Dauda, B. M. \& Kolawole, E. G. (2003). Effect of loom setting on fabrics cover and beat-up force. Indian Journal of Fibres and Textile Research Vol. 28pp. 147-149.

[4] Dauda, B. M. (2004). The Use of yarns for satisfactory construction of textiles. Indian Journal of fibres and textile Research Vol. 29, pp. 339-342.

[5] Ekumankama, I. O. \& Ukah, C. H. (2010). Promoting Entrepreneurship in Akwete Fabric Production in Abia state Nigeria. Journal of Home Economics Research Association of Nigeria. Vol. 12 September

[6] Galuszynski, S. \& Ellis, P. (1983). Some effects of fabric elastic constant on the dynamics of Fabrics formation. The Journal of Textile Institute, Vol. 86 No. 2, pp. 232-240

[7] Gay, L. R. and Diehl, P. L. (1992). Research Methods for Business and Management. https://www.emoderators.com/ipct-j/1998/nz4/hill.html.

[8] Hossain, M. M., Datta, E. and Rahman, S. (2016). A Review on Different Factors of Woven Fabrics' Strength Prediction. Science Research Journal. Vol. 4 No. 3 June, 2016.

[9] Kothari, V. K. (2003) Testing and Quality Management. Indian Journal of Fibre \& Textile Research Vol. 28 No. (1), 29.

[10] Kucha, M. O. I. (1989). The Study of Traditional and Contemporary Production of Akwete cloth and its adaptation to cold weather condition in Abia state Nigeria. A research Work Unpublished.

[11] Lijing, W., Martin, F., Jackie, Y. C. (2011). Study of properties of mechanical compression fabrics. Journal of Fibre Bioengineering and informatics. Vol. 4 No. 1 pp. 92-104.

[12] Otuka, V. U. (2009). Traditional Cloth Wearing in Akwete Guardian Newspaper. http://www.ngraguardiannews.com/lifestyle/article12indien3html. Retrieved 3/5/2018 8:39pm

[13] Singh, Y. K. (2006). Fundamentals of Research Methodology and Statistics. New Delhi New Age International Publishers Limited. 